NBER WORKING PAPER SERIES

IMMIGRATION, INVESTMENT, AND REAL WAGES

Elise S. Brezis

Paul Krugman

Working Paper No. 4563

NATIONAL BUREAU OF ECONOMIC RESEARCH

1050 Massachusetts Avenue

Cambridge, MA 02138

December, 1993

This paper is part of NBER's research program in International Trade and Investment. Any opinions expressed are those of the authors and not those of the National Bureau of Economic Research. 


\title{
IMMIGRATION, INVESTMENT, AND REAL WAGES
}

\begin{abstract}
When a country is the recipient of large-scale, politically motivated immigration -- as has been the case for Israel in recent years -- the initial impact is to reduce real wages. Over the longer term, however, the endogenous response of investment, together with increasing returns, may well actually increase real earnings. If immigration itself is not wholly exogenous, but responds to real wages, there may be multiple equilibria. That is, optimism or pessimism about the success of the economy at absorbing immigrants may constitute a self-fulfilling prophecy.
\end{abstract}

Elise S. Brezis

Department of Economics

Bar-Ilan University

Ramat-Gan

ISRAEL
Paul Krugman

Department of Economics

Massachusetts Institute of Technology Cambridge, MA 02139 and NBER 
Since World war II, a number of countries have experienced surges of politically motivated immigration. Examples include West Germany during the early postwar years, which was the destination of millions of refugees from the East; Portugal, faced during the mid-1970s with the return of several hundred thousand citizens from its newly independent African colonies; and Israel, which absorbed a massive wave of immigrants in the years following independence and has recently received a new surge of immigration from the former Soviet Union.

Such waves of immigration often present considerable short-run economic difficulties, leading to some mix of upward pressure on unemployment and downward pressure on real wages. Nonetheless, over the longer run it is arguable that immigration not only brings considerable benefits, it may well tend to raise real wages. The problem is one of getting through the transition.

The purpose of this paper is to offer a simple model that is suggestive of the mix of difficulties and opportunity presented by large-scale immigration. It shows why immigration may well have a negative effect on real wages in the short run but a positive effect in the long run. It also suggests the possibility that the outcome of waves of immigration is not predetermined: the question of whether the immigrants are successfully absorbed may depend crucially on both policy and expectations.

\section{A simple theoretical model}

The essence of our story is the distinction between a short 
run in which the capital stock is predetermined, and in which there are as a result diminishing returns to labor; and a long run in which the capital stock adjusts, and in which increasing returns at the level of the economy give rise to what is in effect an upwardsloping demand curve for labor.

To tell this story as clearly as possible, we offer a stripped-down model that makes no pretense of realism. It is intended only to offer a minimalist and partial account.

Consider, then, an open economy in which there are two factors of production, capital and labor. We assume that these factors can be combined to produce a generic "input" that can in turn be used in the production of both final and intermediate goods; for simplicity we let the production function for this general input be Cobb-Douglas:

$$
X=A K^{\mu} L^{1-\mu}
$$

We are going to suppose that there are increasing returns to the employment of this input. Rather than simply assume external economies at the level of the economy, however, we derive these increasing returns from a production structure in which "input" is used to produce nontraded intermediate goods, each of which is subject to internal economies of scale; the effect of market size on the monopolistically competitive intermediate goods sector gives rise to de facto external economies at the level of the economy as 
a whole. 1

We assume, then, that final output of a single traded good is produced using a part of the general input and a nontraded composite intermediate good:

$$
Q_{F}=X_{F}^{Y} Q_{I}^{1-Y}
$$

where $Q_{1}$ is a composite of many symmetric differentiated products,

$$
Q_{I}=\left[\sum_{i} z_{i}^{\theta}\right]^{1 / \theta}
$$

Each of these differentiated products is produced from the general input, subject to economies of scale:

$$
x_{i}=\alpha+\beta z_{i}
$$

The total supply of input will be divided between that portion used directly in the final good sector and that part used to assemble nontraded intermediates:

$$
X=X_{F}+\sum_{i} x_{i}=X_{F}+X_{I}
$$

We assume that the final output can be sold on world markets at a fixed price. We also assume that this country is able to borrow or lend freely on world capital markets at a real interest rate in

'This general story, and much of the formal structure of this model, are originally due to Ethier (1982). 
terms of traded goods of $r$. We will, however, assume that there is costly adjustment of the physical capital stock, giving rise to an investment function that depends on the price of capital in place ("Tobin's q"). We write this investment function as

$$
\frac{\dot{K}}{K}=I(q)
$$

where we assume $I^{\prime}>0$ and define $I(1)=0$, that is, assume that the capital stock is constant when $q=1$.

\section{Determination of output and factor prices}

Before we turn to the effects of immigration, we must first show how output and factor prices are determined for given supplies of capital and labor.

We begin asking how the value-added of the economy will be divided between the direct input into the final good $x_{k}$ and the intermediate composite $Q_{1}$. Given the assumed cobb-Douglas form, this is straightforward: a share $\gamma$ of the value-added will be accounted for by direct inputs, $1-\gamma$ by the composite.

But now we note that under a monopolistically competitive market structure (which we will describe in a moment), profits are zero. Thus all value-added accrues to the input $x$, implying in turn that $x$ is allocated between the two activities in the same proportions as value-added: 


$$
\begin{gathered}
5 \\
x_{F}=\gamma X \\
X_{I}=\sum_{i} x_{i}=(1-\gamma) X
\end{gathered}
$$

Next we turn to the market structure within the intermediate goods sector. This is simply the one made familiar by Dixit and stiglitz (1977), in which there are many small firms, each producing a differentiated product. The price of each firm is a markup on marginal cost. If entry takes place until profits are eliminated, there is a unique zero-profit size of firm:

$$
z_{i}=\frac{\alpha}{\beta} \frac{1-\theta}{\theta}
$$

The input per good is therefore also fixed:

$$
x_{i}=\frac{\alpha}{1-\theta}
$$

It follows that the number of differentiated products is simply proportional to the input to the sector:

$$
n_{1}=x_{I}(1-\theta) / \alpha
$$

From (3), (9), and (11) we find that there are increasing returns in the production of the intermediate good, with output of the composite $Q_{1}$ taking the form

$$
Q_{I}=\phi X_{I}^{1 / \theta}
$$

The increasing returns arise because larger input allows the 
production of a greater variety of products.

Increasing returns in the production of the intermediate good translate into increasing returns at the level of the economy as a whole. Suppressing the constant terms, we find first that

$$
Q_{E}=X_{F}^{Y} X_{I}^{\frac{1-\varphi}{\theta}}
$$

which in turn implies that

$$
Q_{F}=\left[K^{\mu} L^{1-\mu}\right]^{\left(\gamma+\frac{1-\gamma}{\theta}\right)}
$$

It may be worth pointing out two things about the increasing returns at the level of the economy shown in (14). First, although these increasing returns apply at the level of the economy and thus look like a pure external economy, in fact they arise from the interaction of economies of scale at the level of the firm with market-size effects. Second, such market-size effects may arise even if the economy appears very open by normal measures -- an important consideration when we are considering the effects of immigration in small countries like Israel, where exports are 45 percent of GDP. The reason is that in this particular model the market size that matters is that for nontraded intermediate goods, not that for final goods. Indeed, in this economy it would be possible to have all final goods exported, which would show up as exports equal to 100 percent of GDP, and still have significant market-size effects giving rise to increasing returns to the 
economy as a whole.

Returning to the model, it is now straightforward to determine factor prices. Given competitive markets for capital and labor, a share $\mu$ of value-added will show up as the income of capital, a share $1-\mu$ as labor income. Thus the rental rate on capital is

$$
R=\mu Q_{F} / K
$$

or

$$
R=K^{\mu\left(\gamma+\frac{1-\gamma}{\theta}\right)-1} L^{(1-\mu)\left(\gamma+\frac{1-\gamma}{\theta}\right)}
$$

and, similarly,

$$
W=(1-\mu) Q_{F} / L
$$

implying

$$
W=K^{\mu\left(\gamma+\frac{1-\gamma}{\theta}\right)} L^{(1-\mu)\left(\gamma+\frac{1-\gamma}{\theta}\right)^{-1}}
$$

Provided that $(1-\gamma) / \theta$ is not too big, that is, that increasing returns at the level of the economy are not too powerful, the demand curve for either factor will be downward sloping if the supply of the other factor is held constant; that is,

$$
\partial R /\left.\partial K\right|_{L}<0 \quad \partial w /\left.\partial L\right|_{K}<0
$$

Before leaving the subject of factor prices, we should note 
that what is determined by $(16)$ is the rental rate on capital; because the price of capital in place, $q$, may vary, this is not the same thing as the rate of return. In fact, given our assumption of perfect capital mobility, the expected rate of return must always equal the international rate $r$. The capital-pricing equation is

$$
r q=R+q
$$

which can be interpreted as a dynamic equation for $q$,

$$
q / q=r-R / q
$$

We are now prepared to analyze the economic impacts of immigration.

\section{The dynamics of exogenous immigration}

We first consider the effects of an exogenous increase in L. This may be thought of as representing a situation in which potential immigrants are relatively unresponsive to economic incentives, and will come regardless of the real wages they expect to receive.

In the short run, with $K$ predetermined, an increase in $L$ will drive down real wages. Over time, however, the capital stock will rise. Since the capital stock will grow as long as $q>1$, in the long run we must have $q=1$. This in turn implies that in the long run $R=r$. 
Two points may now be noted. First, because of increasing returns, the percentage rise in the capital stock following an increase in the labor force will be more than proportional: because of the increase in final output per unit of input, the capitallabor ratio must actually rise in order to prevent a rise in $R$. By substituting $R=r$ into (16), we find that

$$
\frac{d K}{K}=\frac{d L}{L} \frac{(1-\mu)\left[\gamma+\frac{1-\gamma}{\theta}\right]}{1-\mu\left[\gamma+\frac{1-\gamma}{\theta}\right]}>\frac{d L}{L}
$$

Second, in the long run the wage rate will rise, both because of the direct effect of increasing returns and because of the induced rise in the capital-labor ratio. We can show that once the capital stock has fully adjusted,

$$
\frac{d w}{w}=\frac{d L}{L} \frac{(1-\gamma)(1-\theta)}{\theta-\mu(1-\gamma(1-\theta))}>0
$$

To reach this long-run favorable outcome, however, the economy must go through a possibly difficult transition. Figure 1 illustrates the dynamics of the economy with an exogenous labor force. The schedule $\mathrm{dK} / \mathrm{dt}=0$ is a horizontal line at $q=1$. The schedule $\mathrm{dq} / \mathrm{dt}=0$ is the locus of points along which $R=r$. The basic picture is the familiar one of saddle-path instability, with a unique path to the long-run equilibrium.

suppose that the economy experiences a sudden one-time increase in the labor force $L$. We know that this will initially 
reduce the real wage rate. Let $d q / d t=0$ in Figure 1 refer to the situation following the labor force increase, so that the initial position is at point 1 and the final position at point 3. Then it is clear that the impact effect of the rise in the labor force is to push the economy to point 2: the price of capital in place jumps, and there is a resulting rise in the investment rate. As the capital stock rises, real wages will rise as well, eventually surpassing their original level.

We see, then, that an exogenous increase in the labor force leads first to a drop in real wages, but then to a surge in investment which gradually raises wages again. In our model, the eventual impact on real wages is actually positive: because the enlargement of the domestic economy allows production of a wider range of nontraded inputs, the real wage in the end rises by more than the initial drop. Increasing returns could, of course, take a variety of other forms as well (for example, in nontraded consumer goods; or for that matter growth in the domestic market might allow efficient substitution of domestic production for imports). Whatever the nature of the increasing returns, however, they make it likely that exogenous immigration which poses short-run difficulties will be beneficial to all workers in the long run. 
4. Endogenous immigration

In reality, immigration is rarely completely exogenous to economic factors. Migrants may choose to stay home, or to seek alternative destinations, and these choices will depend on the economic opportunities they perceive. But the long-run economic opportunities depend on the increase in the labor supply and in the stock of capital.

This endogeneity in the amount of migration raises some important possibilities: the economy may exhibit multiple equilibria, with a possible role for government policies to stimulate investment or even the possibility of sheer selffulfilling expectations.

To analyze these possibilities, we introduce a very simple and extreme endogeneity of migration. We assume that there is an initial labor force $L_{0}$, with an initial wage $w_{0}$. There is a pool of potential immigrants of size $M$. All of these migrants are willing to come if and only if they receive a wage rate greater than $w_{M}>$ $w_{0}$.

It is immediately apparent from this assumption that one possibility is zero immigration: as long as $L=L_{0}$, the wage rate is too low to attract the immigrants and there is no incentive to invest. There may, however, also be a steady state in which all of the immigrants come. As we saw in the previous section, if $L$ rises the long-run real wage will also rise. Suppose that with a labor force $I_{0}+M$ and with the capital stock large enough so that $R=r$ 
the real wage exceeds $w_{M}$. Then it is clear that if all of the migrants can be persuaded to come and equipped with their long-run capital stock, they will be paid enough to persuade them to stay.

But will the economy get there from here? To answer that, we need to look at the dynamics.

Figure 2 illustrates the relationship between $R$ and $K$ when there is endogenous immigration. The shape of the curve may be understood as follows. First, point 0 represents the initial equilibrium of the economy. For $K$ in the vicinity of this initial level, the wage rate is too low to attract immigrants, and thus the labor force is fixed at $L_{0}$. Given a fixed labor force, $R$ is a decreasing function of $\mathrm{K}$.

For some sufficiently large $k$, however, the wage rate equals $w_{M}$. At this point, shown as $k_{1}$ any rise in $k$ will be accompanied by a rise in $L$ rather than a rise in $w$. If we assume that the labor force rises so as to keep $w=w_{M}$, we find that

$$
\frac{d L}{L}=\frac{d K}{K} \frac{\mu\left(\gamma+\frac{1-\gamma}{\theta}\right)}{1-(1-\mu)\left(\gamma+\frac{1-\gamma}{\theta}\right)}>\frac{d K}{K}
$$

The combination of a rising ratio of labor to capital and increasing returns will imply a rising rental rate on capital:

$$
\frac{d R}{R}=\frac{d K}{K} \frac{(1-\gamma)(1-\theta)}{\theta-(1-\mu)(1-\gamma(1-\theta))}>0
$$

This upward-sloping segment of the curve does not, however, go 
on indefinitely. At some level of capital, shown as $k_{3}$, the pool of potential immigrants is exhausted. Any further increase in capital will drive $w$ up and $R$ down, so that the schedule is now downwardsloping again, reaching $R=r$ at $K_{4}$.

There are several potential dynamic pictures associated with a schedule of this shape, each with a clear economic interpretation. We show them in Figures 3,4 , and 5 .

To understand these figures, we first consider the dynamics of the system in the vicinity of the three equilibrium points 0,1 and 2. Points 0 and 2 are evidently saddle-path-unstable. In the vicinity of point 1 , the linearized dynamic system takes the form

$$
\begin{gathered}
\dot{K}=I^{\prime}(q-1) \\
\dot{q}=R^{\prime} K_{1}\left(K-K_{1}\right)-r(q-1)
\end{gathered}
$$

The roots of this system are

$$
\begin{aligned}
& \lambda_{1}=\frac{r+\sqrt{r^{2}-4 R^{\prime} I^{\prime} K_{1}}}{2} \\
& \lambda_{2}=\frac{r-\sqrt{r^{2}-4 R^{\prime} I^{\prime} K_{1}}}{2}
\end{aligned}
$$

If $R^{\prime} I^{\prime} K_{1}$ is not too large - that is, if increasing returns are weak and/or investment is not too responsive to incentives -then both roots are positive and real. In that case, we get Figure 
3. There is a unique value of $q$ for each $K$; if $K$ exceeds $K_{1}$, the economy will end up attracting and holding all of the potential migrants, but if $K$ starts smaller than $K_{1}$ the potential immigratns will fail to come.

If increasing returns are large and/or the adjustment of the capital stock fast, the roots for the system in the vicinity of $k$, are complex. This gives us either Figure 4 or, in an extreme case, Figure 5. In Figure 4 there is a range of initial capital stocks from which self-fulfilling expectations can lead the economy to either steady state. In Figure 5 this range expands to fill the whole space. (For a discussion of similar dynamics, see Matsuyama (1991)).

What is the economic interpretation of these cases? Consider the two extreme cases as represented by Figures 3 and 5 .

In the case shown in Figure 3 , the market left to itself will shut out the possibility of large immigration. Potential migrants will not have any incentive to come given the low wage; investors will not put in more capital given the absence of any increase in the labor force. The only possible way to attract migrants would be through deliberate government policy. In particular, if some policy such as an investment subsidy could raise $K$ to the level $K_{2}$ or higher, the economy would continue to grow until all potential immigrants had come.

In the case shown in Figure 5 , by contrast, optimism about the economy's prospects can be self-fulfilling: if investors believe that other investors will also put capital into the country in 
sufficient quantities, they will put in enough to draw in the potential migrants. The gains from having a larger economy then justify this investment.

The intermediate case in Figure 4 is one in which the critical level of capital necessary to achieve the high-level equilibrium is itself a little fuzz; there is a range of capital stocks from which the economy could manage to attract and hold the potential immigrants, but only above the top end of that range is this outcome necessary.

\section{Conclusions}

When political disruptions lead to large-scale immigration, the inflow of labor inevitably seems at first like a major economic burden. The economic difficulties experienced by initial waves of migrants may even serve as a deterrent to subsequent waves, as has apparently been the case for former soviet residents considering a move to Israel. Yet if there are significant increasing returns in the economy, as there may well be even in nations with high shares of trade in GDP, the long run impact of immigration will often be to raise rather than lower real wages.

In this paper we have offered a simple formalization of the contrast between a difficult short run and a benign long.run for countries experiencing large-scale immigration. We have also shown that when immigration is itself affected by the state of the host economy, success in the transition to that long run is not assured. 
Investor confidence, and possibly an active government program to promote investment, may be crucial if a potential destination for large immigration is to fulfil that potential.

\section{REFERENCES}

Dixit, A. and Stiglitz, J. (1977), "Monopolistic competition and optimum product diversity", American Economic REview 67: 297-308.

Ethier, w. (1982), "National and international returns to scale in the modern theory of international trade", American Economic Review $72: 389-405$.

Matsuyama, K. (1991), "Increasing returns, industrialization, and indeterminacy of equilibrium", Quarterly Journal of Economics $106: 617-50$. 
</ref_section> 


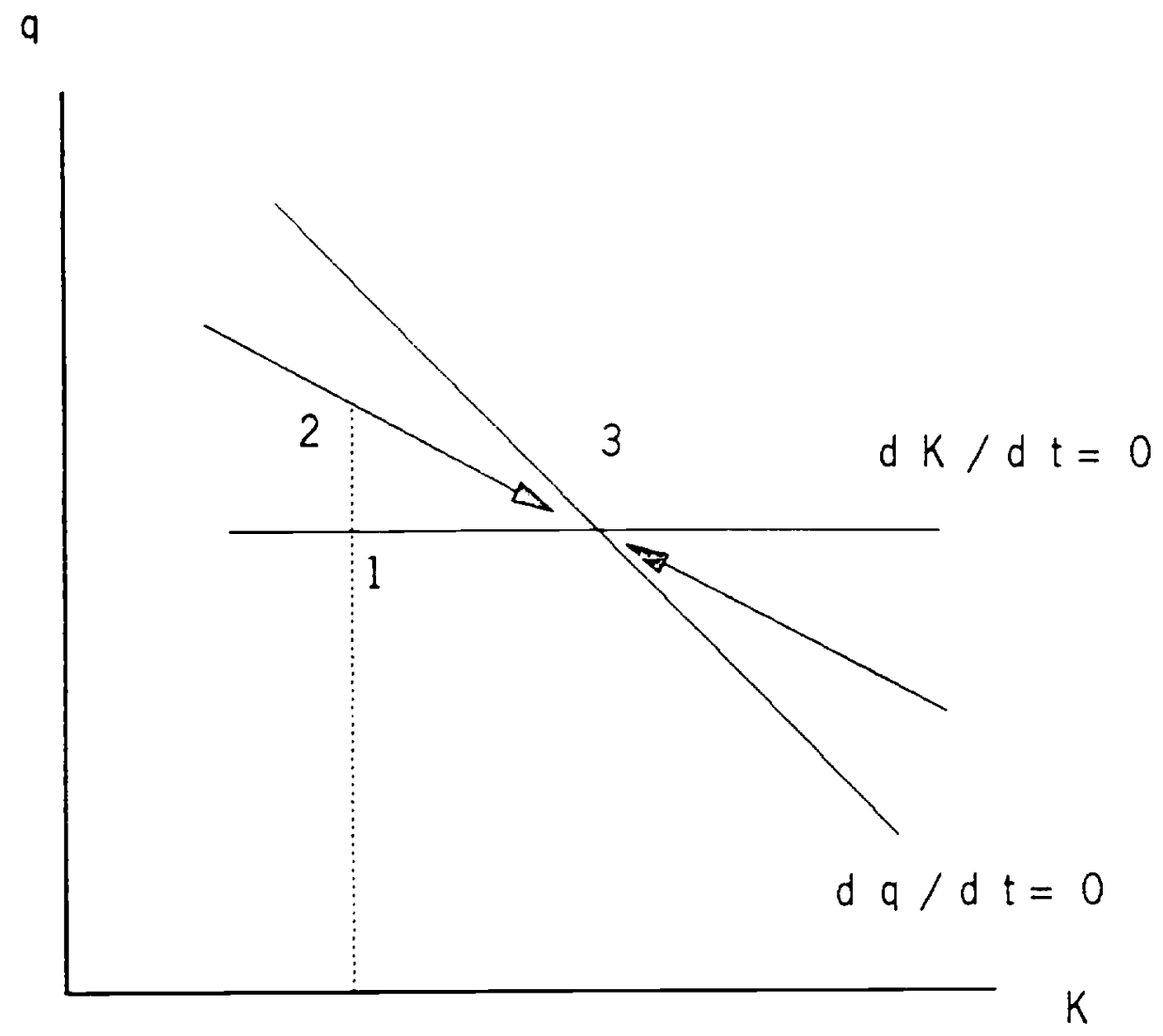

FIG URE I 


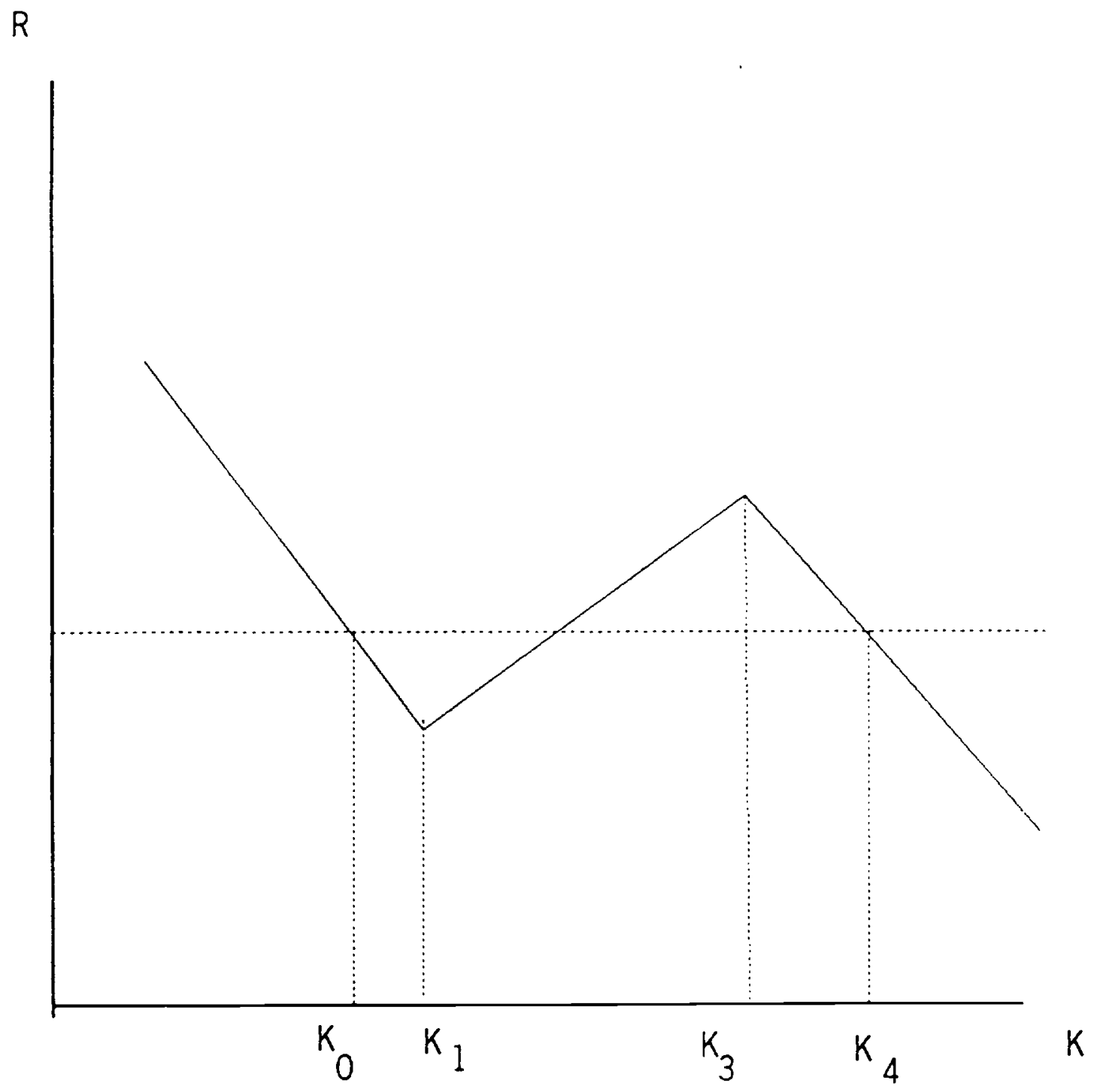

FIGURE 2 


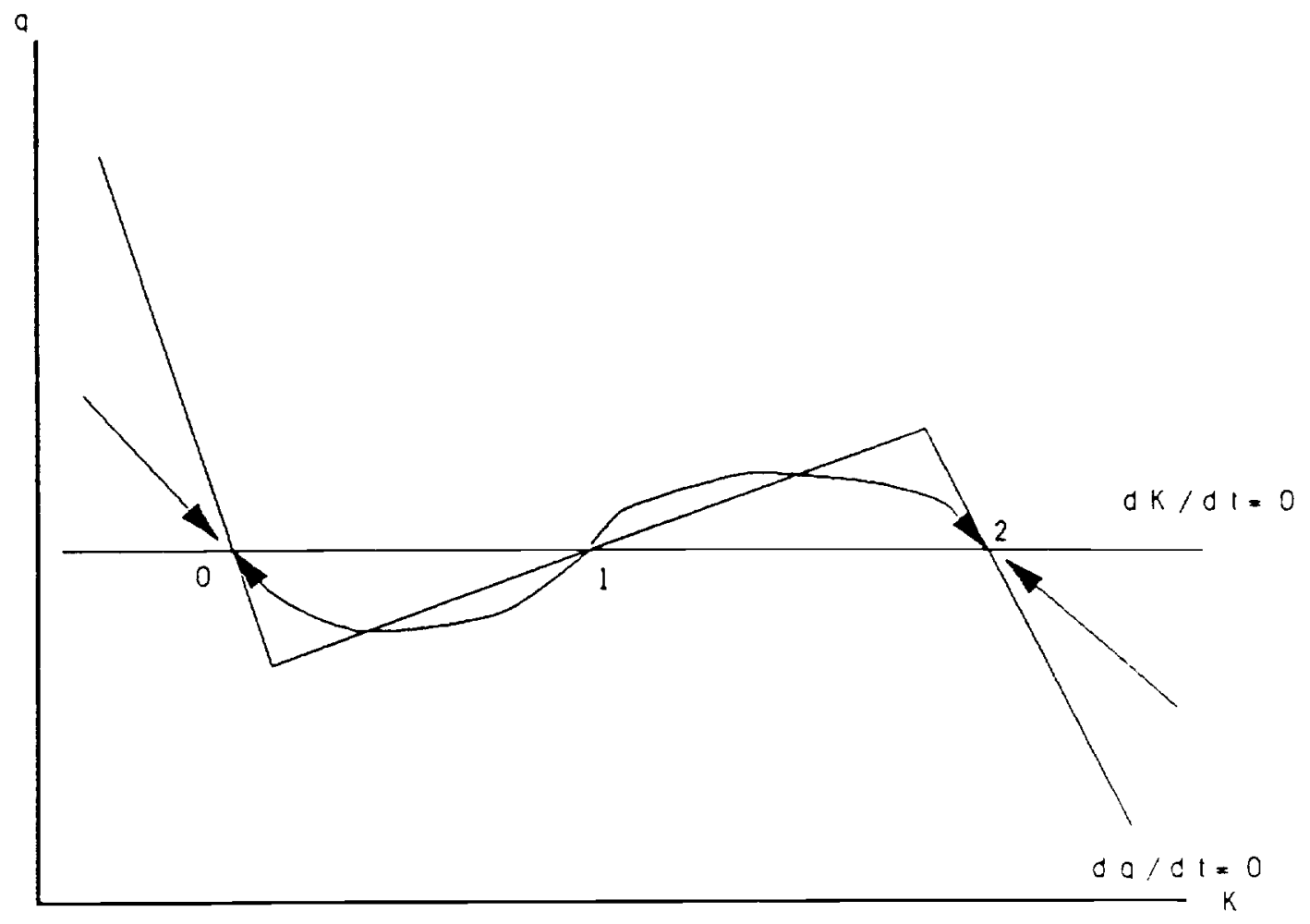

FIGURE 3 


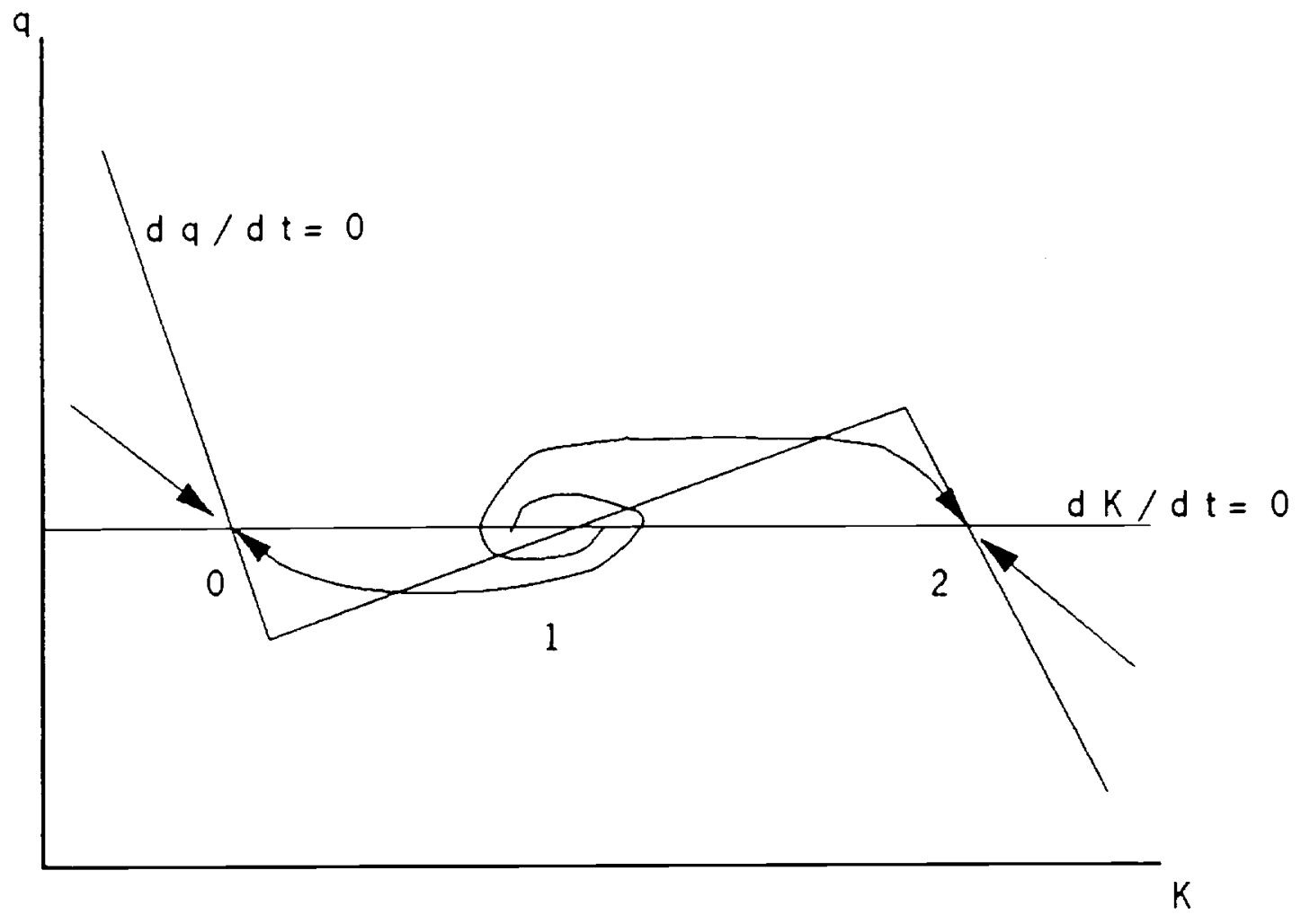

FIGURE 4 


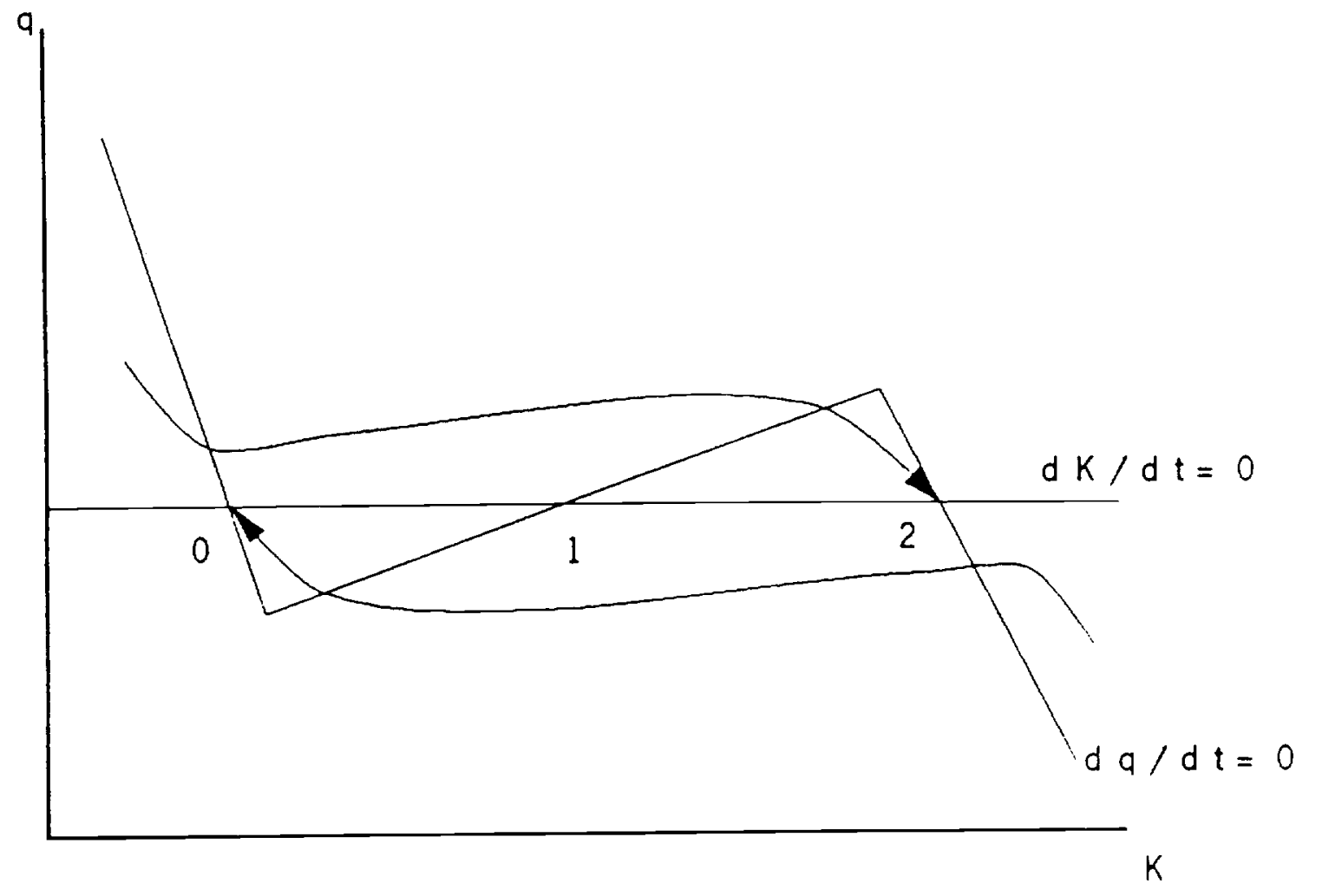

FIGURE 5 